\title{
COVID-19 in people with rheumatic diseases: risks, outcomes, treatment considerations
}

\author{
Rebecca Grainger ${ }^{1}$, Alfred H. J. Kim (i) ${ }^{2}$, Richard Conway ${ }^{3}$, Jinoos Yazdany (1) ${ }^{4}$ \\ and Philip C. Robinson $\mathbb{1 0}^{5,6 凶}$
}

Abstract | The COVID-19 pandemic has brought challenges for people with rheumatic disease in addition to those faced by the general population, including concerns about higher risks of infection with severe acute respiratory syndrome coronavirus 2 (SARS-CoV-2) and poor outcomes of COVID-19. The data that are now available suggest that rheumatic disease is associated with a small additional risk of SARS-CoV-2 infection, and that outcomes of COVID-19 are primarily influenced by comorbidities and particular disease states or treatments. Despite considerable advances in our knowledge of which therapeutic agents provide benefits in COVID-19, and of what constitutes effective vaccination strategies, the specific considerations that apply to people with rheumatic disease are yet to be definitively addressed. An overview of the most important COVID-19 studies to date that relate to people with rheumatic disease can contribute to our understanding of the clinical-care requirements of this population.

${ }^{'}$ Department of Medicine, University of Otago, Wellington, New Zealand.

${ }^{2}$ Division of Rheumatology, Department of Medicine, Washington University School of Medicine, St Louis, MO, USA.

${ }^{3}$ Department of Rheumatology, St James's Hospital, Dublin, Ireland.

"Division of Rheumatology, Department of Medicine, San Francisco General Hospital, University of California, San Francisco, CA, USA.

${ }^{5}$ University of Queensland School of Clinical Medicine, Faculty of Medicine, Herston, Queensland, Australia.

${ }^{6}$ Royal Brisbane \& Women's Hospital, Metro North Hospital \& Health Service, Herston Road, Herston, Queensland, Australia.

凶e-mail:philip.robinson@ uq.edu.au

https://doi.org/10.1038 s41584-022-00755-x
Cases of what would later be named COVID-19 were identified in December 2019. The sequence of severe acute respiratory syndrome coronavirus 2 (SARS-CoV-2) was available shortly afterwards, and the health-system and public-health responses have been a global focus for the past 2 years. Although several effective therapeutics have been identified, vaccines hold the greatest promise for effective management of the pandemic. The rapid development and deployment of highly effective vaccines against SARS-CoV-2 has been one of the greatest scientific achievements of our time ${ }^{1}$.

At the beginning of the COVID-19 pandemic, it was not known whether people with rheumatic disease (autoimmune and/or inflammatory disease affecting joints and/or muscles) would be at a higher risk of poor outcomes than the general population. Immunological alteration as a direct result of rheumatic disease or an indirect effect of treatment has the potential to contribute to poor COVID-19 outcomes ${ }^{2}$. Although vaccination against SARS-CoV-2 reduces symptomatic COVID-19 infection rates and poor outcomes in the general population, vaccination has additional considerations for people with rheumatic disease, including sub-optimal vaccine responses that reduce seroconversion rates, and rheumatic-disease flare ${ }^{3,4}$. Notably, clinical development and phase III efficacy trials for SARS-CoV-2 vaccines did not include people with rheumatic disease $\mathrm{s}^{5}$. Therefore, initial vaccination recommendations were based on first principles or extrapolated from experience with vaccinations against diseases such as influenza. In the second year of the pandemic, multiple research efforts have begun to fill the data deficit. In this article, we provide an overview of the COVID-19 research findings that have the greatest relevance to people with rheumatic disease. We describe the risks of SARS-CoV-2 infection, the outcomes of COVID-19 (including factors associated with poor outcomes) and the management of COVID-19, and provide an overview of relevant vaccination strategies and considerations.

\section{SARS-CoV-2 infection}

Upon SARS-CoV-2 infection, initial COVID-19 disease is caused by intracellular viral replication and virus-mediated cell death with associated immunological host responses. Infected individuals are generally either asymptomatic or have mild symptoms, such as headache, fever, fatigue and sore throat. A small proportion of those who are infected progress to severe illness resulting from a pathogenic host response with a hyperinflammatory state and multi-organ damage ${ }^{6,7}$.

SARS-CoV-2 is transmitted from person to person via the aerosol and droplet routes ${ }^{8}$. Maternal-to-fetal in utero transmission and fomite-based transmission might also occur, but are probably rare $^{8}$. Susceptibility to SARS-CoV-2 infection is influenced by viral, host and environmental factors ${ }^{8}$. Age seems to be the most important determinant of host infection risk, possibly reflecting age-related variation in respiratory tract expression 


\section{Key points \\ - People with immune or inflammatory rheumatic disease might have a higher risk of infection with SARS-CoV-2 after exposure than the general population, although the additional risk is probably small. \\ - Risk of poor COVID-19 outcomes in patients with rheumatic disease seems to be mediated by the presence of comorbidities, treatment with glucocorticoids or rituximab, and high disease activity. \\ - People with immune or inflammatory rheumatic disease who experience mild COVID-19 symptoms should stop taking immunomodulating medications for 1-3 weeks from the onset of disease. \\ - People with rheumatic disease with positive SARS-CoV-2 test results or mild COVID-19 symptoms and risk factors for poor outcomes should stop taking immunomodulating medications and consider treatment with antiviral medications. \\ - Most patients with treated rheumatic disease generate antibody responses to SARS-CoV-2 vaccines, but medications such as B cell-depleting therapies and mycophenolate confer a high risk of poor responses. \\ - People with immune or inflammatory rheumatic disease are strongly recommended to receive SARS-CoV-2 vaccination, including booster doses if recommended, despite some evidence of a diminished response in particular groups.}

of angiotensin-converting enzyme 2 receptor, a cellular receptor for SARS-CoV-2 binding ${ }^{9,10}$. Environmental conditions, including poor ventilation and overcrowding, are risks for high viral infection rates ${ }^{11,12}$, and their possible contribution to superspreading events is a particular concern ${ }^{11,13}$. Practical steps that can reduce infection risk include the avoidance of locations where such conditions occur, maintenance of social and/or physical distancing, appropriate hand hygiene and the use of face masks ${ }^{14}$. These measures are also key elements for people with rheumatic disease to reduce their risk of infection. In addition to such general considerations, it is important to understand whether any additional risk of SARS-CoV-2 infection is specifically conferred by rheumatic disease or its treatments.

Several studies have produced comparative SARSCoV-2 infection rates for individuals with rheumatic disease and for the general population. In an early study from Wuhan in China, a worryingly high relative risk of infection was observed for people with rheumatic disease compared with the general population (OR 10.90; 95\% CI 5.43-21.89) ${ }^{15}$. Notably, however, this analysis was based on a low number of people with rheumatic disease and COVID-19 diagnoses, resulting in a wide confidence interval. In a multicentre study of individuals in Hubei province in China, in households with a confirmed diagnosis of COVID-19, the rate of infection among family members with rheumatic disease was higher than that among family members without rheumatic disease (OR 2.68; 95\% CI 1.14-6.27) ${ }^{16}$. In a large, retrospective, hospital-based, multicentre study conducted in Spain during the first wave of SARS-CoV-2 infection in 2020, people with rheumatic disease had a $30 \%$ higher risk of infection than the wider population ${ }^{17}$. Similarly, in a cohort study from South Korea, the risk of SARS-CoV-2 infection in patients with rheumatic disease was higher than in matched individuals without rheumatic disease (adjusted OR 1.19; 95\% CI 1.03-1.40) ${ }^{18}$. By contrast, in population-based cohort studies from Korea and Italy, no definite increase was observed in the risk of SARS-CoV-2 infection for people with rheumatic disease $\mathrm{e}^{19,20}$. The interpretation of these data is complicated by potential confounding resulting from the effects of comorbidities, medication, rheumatic-disease activity and health behaviours in this group.

The risks of SARS-CoV-2 infection have been examined in specific rheumatic diseases. In a case-control study from Italy, the estimated risk of infection was $64 \%$ higher for people with rheumatoid arthritis (RA) than for the general population, but there was no increase in the risk for people with connective tissue disease $(\mathrm{CTD})^{21}$. Analysis of the UK Biobank dataset of nearly half a million people found that individuals with gout had a risk of infection that was no higher than those without gout, whereas those with RA had a point estimate of $34 \%$ higher risk than those without RA ${ }^{22}$. Similarly, in a study of 33,886 people with RA in the US Veterans Affairs system, the risk of COVID-19 diagnosis was $25 \%$ higher than in 33,886 people without $\mathrm{RA}^{23}$. The heterogeneity in these results might reflect differences in study design or in SARS-CoV-2 testing rates, which are influenced by multiple personal and health-system factors. Further data on risk in rheumatic-disease subsets is becoming available, and more information of this nature will, over time, help to provide a more granular picture $^{24,25}$.

In summary, the available evidence (mostly from retrospective analyses) indicates that there might be a small elevation of the risk of SARS-CoV-2 infection in people with rheumatic disease, with the caveat that these data have inherent limitations. Notably, in a meta-analysis of the 23 studies published up until mid-February 2021 that reported SARS-CoV-2 infection rates in people with rheumatic disease, the relative risk compared with the general population was 1.52 (95\% CI $1.16-2.00)^{26}$. Regardless of the risk of infection, it is also important to know whether people with rheumatic disease have worse outcomes from COVID-19.

\section{COVID-19 outcomes in rheumatic disease}

For many people, COVID-19 is a self-limiting viral illness. However, severe COVID-19 can cause pneumonitis, acute respiratory distress syndrome, renal failure, thrombotic complications, cytokine storm ${ }^{27}$, multi-organ failure and death ${ }^{28}$. Overall, infection fatality rates range from 0.5 to $2.7 \%$, and they are influenced by the presence of risk factors for poor outcomes. Non-rheumatic disease factors can affect the risk of death from COVID-19 in people with rheumatic disease ${ }^{29,30}$. Therefore, studies in which the methods adjust for confounding factors that might influence COVID-19 outcomes are the most informative. The limitations of many studies in this rapidly moving field also mean that we must interpret data cautiously.

Many of the large population-based or health-systembased studies conducted to date have reported point estimates suggesting elevation of the risk of COVID-19 hospitalization or death in people with rheumatic disease (TABLE 1). In a large Danish population-based study of 11,122 individuals with SARS-CoV-2 infection confirmed by PCR in early 2020, people with RA or CTD had higher odds of hospitalization or death than those without these conditions, using an unadjusted model ${ }^{31}$. 
However, with adjustment for age, sex and comorbidities, there were no higher odds of these poor outcomes $^{31}$. In a subsequent Danish data-linking study for a 6-month period from March 2020, the risk of hospitalization with COVID-19 was $46 \%$ higher for people with rheumatic disease than for the general population, but, using a fully adjusted model, only people with RA still had an elevated risk of a severe outcome (HR 1.72; 95\% CI 1.29-2.30) $)^{32}$. In a study of 17 million adults in the UK primary care database OpenSAFELY, the risks of COVID-19-associated death for the combined group of people with RA, systemic lupus erythematosus (SLE) or psoriasis were slightly higher than for the general population $^{33}$. Similarly, in the UK Biobank study, compared with unaffected individuals, the risk of COVID-19associated death was elevated for people with RA, but not for those with gout ${ }^{22}$. In an analysis of $>31,000$ adults in a US electronic medical-record database (TriNetX), elevation of the risk for COVID-19 death was not significant (OR 1.17; 95\% CI 0.85-1.60) for people with rheumatic disease $^{34}$. Among $>30,000$ patients with RA and the same number of matched comparators from the US Veterans Affairs health-care system, the risk of hospitalization or death was higher for patients with RA (HR 1.35; 95\% CI 1.10-1.66 $)^{23}$. In other, smaller, comparative cohort studies, estimates of the risks of poor outcomes have varied. A small, but well-conducted US-based cohort study of 143 people with rheumatic disease and 688 matched comparators reported hazard ratios of 0.87 (95\% CI 0.68-1.11) for hospitalization, 1.27 (95\% CI 0.86-1.86) for intensive-care unit (ICU) admission, 1.51 (95\% CI 0.93-2.44) for mechanical ventilation and 1.02 (95\% CI 0.53-1.95) for death ${ }^{35}$. By contrast, in a US-based multicentre comparative cohort study that also used the TriNetX dataset, researchers reported an increased risk of hospitalization (relative risk (RR) 1.14; 95\% CI 1.03-1.26) and ICU admission (RR 1.32; 95\% CI 1.03-1.68), but not mechanical ventilation (RR 1.05 ; 95\% CI $0.77-1.44$ ) or death (RR 1.08; 95\% CI 0.81-1.44) for people with rheumatic disease compared with matched comparators ${ }^{36}$. When the model was expanded to incorporate comorbidities and health-care utilization, the risks were attenuated. In a South Korean study involving 8,297 patients with autoimmune inflammatory rheumatic diseases, the risk of COVID-19-related death was greater than in a matched cohort without rheumatic disease (adjusted OR 1.69; $95 \%$ CI 1.01-2.84) ${ }^{18}$. A similar risk of death (OR 1.74; 95\% CI 1.08-2.79) was identified in a meta-analysis of 13 studies published up to mid-February 2021, whereas the risks of hospitalization (OR 1.25; 95\% CI 0.68-2.31), ICU admission (OR 1.16; 95\% CI 0.62-2.18) and mechanical ventilation (OR 1.58; 95\% CI 0.88-2.84) were not significantly different in individuals with and those without rheumatic and musculoskeletal diseases (RMDs), although point estimates all showed the same direction of effect $^{26}$. Overall, the results of the individual studies, supported by the meta-analysis, indicate that compared with the general population, people with rheumatic disease are at an increased risk of hospitalization, and potentially of other severe outcomes of COVID-19, with some of the risk being attributable to comorbidities. The high incidence among people with rheumatic disease of comorbidities that are known to be associated with poor outcomes of COVID-19 indicates that a detailed focus on the influence of these factors is essential. The COVID-19 Global Rheumatology Alliance (C19-GRA) physician-reported registry of people with rheumatic disease and COVID-19 was launched at the beginning of the pandemic, and has provided further insights into COVID-19 outcomes for people with rheumatic disease ${ }^{37-39}$.

Table 1 | Reports of COVID-19 hospitalization or death risks in people with rheumatic disease

\begin{tabular}{|c|c|c|c|c|c|}
\hline $\begin{array}{l}\text { Study } \\
\text { location }\end{array}$ & Rheumatic disease population ( $n$ ) & Comparator population (n) & $\begin{array}{l}\text { Hospitalizationa; } \\
\text { OR/HR/RR (95\% Cl) }\end{array}$ & $\begin{array}{l}\text { Deatha } ; \text { OR/ } \\
\text { HR }(95 \% \mathrm{Cl})\end{array}$ & Ref. \\
\hline Denmark & $\begin{array}{l}\text { RA, CTD with PCR test ( } 348 \text { SARS-CoV-2 } \\
\text { positive, } 13,498 \text { negative) }\end{array}$ & $\begin{array}{l}\text { General population with PCR test } \\
(11,122 \text { positive, } 410,697 \text { negative })^{b}\end{array}$ & OR $1.5(1.1-1.9)$ & OR $1.1(0.8-1.6)$ & 31 \\
\hline Denmark & RA, spondyloarthritis, CTD, vasculitis $(58,052)$ & General population $(\sim 4.5 \text { million })^{b}$ & HR $1.46(1.15-1.86)$ & NR & 32 \\
\hline South Korea & $\begin{array}{l}\text { Inflammatory arthritis, CTD with PCR test } \\
(8,297)\end{array}$ & $\begin{array}{l}\text { General population with PCR test } \\
(133,609)^{\mathrm{b}}\end{array}$ & NR & $\begin{array}{l}\text { OR } 1.69 \\
(1.01-2.84)\end{array}$ & 18 \\
\hline UK & $\begin{array}{l}\text { RA, systemic lupus erythematosus, psoriasis } \\
(878,475)\end{array}$ & General population $(17,278,392)^{b}$ & NR & $\begin{array}{l}\text { HR } 1.19 \\
(1.11-1.27)\end{array}$ & 33 \\
\hline UK & RA $(5,409)$, gout $(13,105)$ & General population $(473,139)^{b}$ & NR & $\begin{array}{l}\text { RA OR } 1.9 \\
(1.2-3.0), \text { gout } \\
\text { OR } 1.2(0.8-1.7)\end{array}$ & 22 \\
\hline USA & Rheumatic disease (681) & $\begin{array}{l}\text { COVID-19-positive general } \\
\text { population }(31,461)^{\mathrm{b}}\end{array}$ & NR & $\begin{array}{l}\text { OR } 1.17 \\
(0.85-1.60)\end{array}$ & 34 \\
\hline USA & Rheumatic disease (143) & $\begin{array}{l}\text { Patients from same hospital } \\
\text { without rheumatic disease }(688)^{c}\end{array}$ & OR $0.87(0.68-1.11)$ & $\begin{array}{l}\text { OR } 1.02 \\
(0.53-1.95)\end{array}$ & 35 \\
\hline USA & $\begin{array}{l}\text { Autoimmune rheumatic disease and } \\
\text { COVID-19 }(2,379)\end{array}$ & $\begin{array}{l}\text { Matched individuals with } \\
\text { COVID- } 19 \text { without autoimmune } \\
\text { rheumatic disease }(2,379)^{c}\end{array}$ & RR $1.14(1.03-1.26)$ & $\begin{array}{l}\text { RR } 1.08 \\
(0.81-1.44)\end{array}$ & 36 \\
\hline USA & RA $(33,886)$ & Individuals without RA $(33,886)^{c}$ & $\begin{array}{l}\text { HR } 1.35(1.10-1.66) \text { for } \\
\text { or death }\end{array}$ & nospitalization & 23 \\
\hline
\end{tabular}


Table 2 | Studies from the COVID-19 Global Rheumatology Alliance reporting outcomes in patients with rheumatic disease

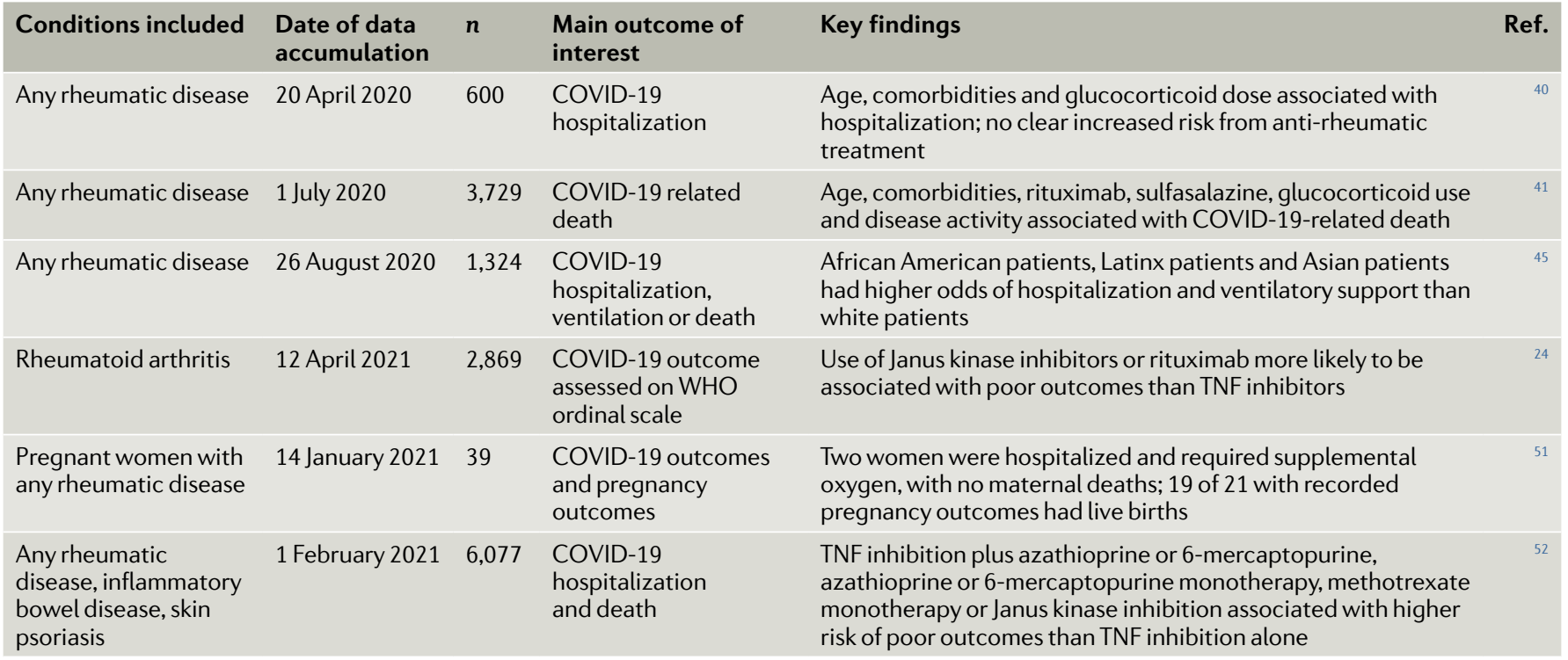

The C19-GRA registry now has $>20,000$ records from individuals in 81 countries, each of which has detailed demographic and clinical data about the rheumatic disease, its treatments and the COVID-19 disease course $^{37,38}$. Among the first 600 records (up to April 2020), 277 individuals (46\%) were hospitalized ${ }^{40}$, and among 3,729 reports to the end of June 2020, there were 390 deaths $(10.5 \%)^{41}$. Although voluntary reporting registries are not appropriate for estimation of rates of poor outcomes, because of selection and other biases, the strength of this dataset is the large number of reports, compiled from many countries, providing an opportunity to evaluate risk of poor outcomes in people with rheumatic disease. This broad reach of the C19-GRA is a strength in terms of external validity, but also a potential limitation in application of the results to any individual country or setting; the C19-GRA collects data from countries that vary greatly in terms of ethnicity, socioeconomic conditions and health-care systems.

In the analysis of the cohort of 3,729 patients with rheumatic disease recorded in the C19-GRA registry up to June 2020 (1,105 (29.6\%) from North America and 2,315 (62\%) from Europe) in which COVID-19-related death was the outcome, the risk of death was associated with age, comorbidity and glucocorticoid use $(\geq 10 \mathrm{mg}$ prednisone-equivalent daily $)^{41}$ (TABLE 2). Similar factors were identified as being associated with risk of hospitalization in the analysis of the first 600 records $^{40}$. Rheumatic-disease factors that were associated with the risk of death included disease activity, rituximab use and sulfasalazine use $\mathrm{e}^{41}$. The results of a post hoc analysis suggested that the association of glucocorticoid use with the risk of death might be the result of confounding by indication, and that underlying disease activity was influencing the risk of COVID-19-related death ${ }^{42}$. An alternative explanation is that use of glucocorticoids during the initial viral-replication stage of COVID-19 might be harmful, and this idea is supported by the observation in the RECOVERY trial of a trend towards poor outcomes in people who did not require oxygen and were treated with dexamethasone ${ }^{43,44}$.

Four further studies from the C19-GRA have provided important additional information. The first was an examination of outcomes by ethnicity in patients with rheumatic disease in the USA up to August 2020 $\left(\right.$ REF $\left.^{45}\right)$. African American, Latinx and Asian patients all had higher odds of requiring ventilatory support and of hospitalization for COVID-19 than white patients. Similarly, data from the general population have identified poor outcomes in many non-white groups ${ }^{46,47}$, and these findings reinforce the need for rheumatologists to advocate for access to care for patient groups that experience inequitable health outcomes. In the second study, C19-GRA researchers examined the risk of poor outcomes and the influence of the use of targeted synthetic DMARDs and biologic DMARDs (bDMARDs) in a cohort of individuals with RA in the C19-GRA registry $^{24}$. Patients with RA who were receiving a Janus kinase (JAK) inhibitor or rituximab prior to the onset of COVID-19 had higher odds of poor outcomes than those who were receiving TNF-inhibitor therapy. One possible explanation for this result is that, like glucocorticoids, JAK inhibitors in COVID-19 might have divergent effects, depending on the underlying disease, although this idea has not yet been confirmed ${ }^{44,48,49}$. The association of the use of rituximab with poor outcomes was not unexpected, as it was similar to the findings in the main cohort study ${ }^{41}$. Here, however, the magnitude of the risk elevation was better defined, and relative to the use of TNF inhibitors, the risk of poor COVID-19 outcomes (combined end point of hospitalization, ventilatory support or death) with rituximab treatment was clear (OR 4.15; 95\% CI 3.16-5.44) $)^{24}$. Rituximab is a B cell-depleting therapy (BCDT), and BCDTs are also associated with poor outcomes for COVID-19 in people with conditions other than rheumatic diseases ${ }^{50}$. In the third study, researchers reported generally favourable pregnancy outcomes in 39 women with rheumatic 
disease who had COVID-19 whilst pregnant ${ }^{51}$. The fourth study contained an analysis of pooled data from the C19-GRA registry and from international registries for people with COVID-19 and inflammatory bowel disease or skin psoriasis, to examine outcomes for people receiving treatment with TNF inhibitors ${ }^{52}$. In $>6,000$ patients with COVID-19 from 74 countries, the risks of hospitalization or death were higher for those who received TNF inhibitors in combination with azathioprine or 6-mercaptopurine, or who received azathioprine or 6-mercaptopurine monotherapy, methotrexate monotherapy or JAK inhibitor monotherapy than for the patients who received only TNF inhibitors. The implication of these results is that in people with a range of immune-mediated inflammatory diseases, TNF inhibitor monotherapy might confer some benefit with respect to COVID-19 outcomes, and this possibility is currently being further explored in intervention studies of the use of TNF inhibitors to treat COVID-19 $\left(\right.$ REF $\left.^{53}\right)$. These examples demonstrate that the C19-GRA registry has provided useful insights to inform people with rheumatic disease and their health-care providers during the COVID-19 pandemic.

Overall, the available data suggest that the use of many conventional synthetic DMARDs and bDMARDs does not confer increased risk of poor outcomes in COVID-19, which is consistent with the recommendations from the ACR and EULAR to continue current treatment with these agents in the absence of known exposure to SARS-CoV-2 in order to maintain good disease control ${ }^{54,55}$. However, there are some notable exceptions such as rituximab ${ }^{56,57}$, for which the risk of poor outcomes is becoming increasingly apparent. The issue of rituximab use is challenging, because the risk of poor outcomes from COVID-19 must be considered against the severity of the rheumatic disease that is being treated. Rituximab is most commonly used for treatment of diseases such as vasculitis, where the alternative (which is often cyclophosphamide) is likely to carry a similar risk of poor outcomes, although because of the relatively infrequent use of cyclophosphamide this possibility has not been well examined.

The practical application of data relating to COVID-19 in the care of people with rheumatic disease is summarized in clinical guidance from ACR and EULAR ${ }^{54,55}$. People with rheumatic disease should follow recommendations for the general population for reduction of exposure to SARS-CoV-2, and should consult with their rheumatologists to make individualized decisions about rheumatic-disease treatment. Although people with rheumatic disease seem to have some increased risk of poor outcomes from COVID-19 compared with the general population, much of this risk might be the result of the unmodifiable burden of comorbid conditions, with additional risk from some treatments and from active rheumatic disease. It would seem prudent to minimize glucocorticoid use where possible, whilst also maintaining the lowest possible disease activity. If a person with rheumatic disease develops COVID-19, active management of the COVID-19 and the rheumatic disease will need to be addressed, with the approaches summarized in the following section.

\section{Management of COVID-19}

The management of COVID-19 in people with rheumatic disease should be predicated on whether the patient is in the early, viral replication phase or the late, hyperinflammatory phase (FIG. 1 and TABLE 3). Treatments that target viral binding or replication are generally expected to have the greatest effect early in the disease, whereas immunomodulating therapies have a role in later disease. The NIH COVID-19 Guidelines have described the clinical spectrum of SARS-CoV-2 infection severity that guides treatment (BOX 1). In addition to illness severity, the NIH COVID-19 Treatment Guidelines Panel recommends tailoring therapeutic management to the patient's physical location (ambulatory or hospitalized $)^{58}$. Notably, in people who are substantially immunosuppressed, the viral-replication phase can be prolonged, and instances of variant evolution have been described ${ }^{59,60}$. Therefore, treatment recommendations outlined for the general population often need to be customized for high-risk patients with rheumatic diseases. The management of COVID-19 in people with rheumatic disease should therefore be based on the known risk factors for poor outcomes, such as age $>65$ years and the presence of comorbidities, the degree of immunosuppression, clinical severity of COVID-19 and location of care provision. Rheumatology services will need to proactively ensure that health-care systems have monitoring in place for patients with rheumatic disease who have one or more of these characteristics, and that patients know to seek further medical advice early with any deterioration, particularly increased dyspnoea.

Management of outpatients. During the early, viralreplication phase, most people with rheumatic disease and mild symptoms can be observed with appropriate simple self-care, particularly if they are on minimal immunosuppression and do not have major comorbidities. The ACR recommends temporarily stopping most immunosuppressive medications in people with COVID-19 for 7-14 days after symptom resolution or 10-17 days after a positive SARS-CoV-2 test ${ }^{61,62}$. EULAR recommends an individualized approach to rheumatic-disease medication use in infected people ${ }^{55}$. In the general population, $100 \%$ of infected people have produced anti-SARS-CoV-2 antibodies within 19 days of infection ${ }^{63}$; thus, prolonged holding of medication in people who are recovering does not seem justified.

In patients with rheumatic disease who are at a risk of clinical deterioration, monoclonal antibodies targeting virus receptor-binding domains or viral replication can be considered early in the disease, usually in the first 10 days after the onset of symptoms. Neutralizing monoclonal-antibody therapy directed at the spike binding-protein components of SARS-CoV-2 can reduce COVID-19 progression in outpatients ${ }^{64-67}$. Although clinical trials to date have not included large numbers of people with rheumatic disease or who were receiving immunocompromising medication, this antiviral strategy would theoretically remain effective in these clinical settings. Several oral antiviral therapies are available for use, including molnupiravir and ritonavir-boosted 
Prior to symptomatic or confirmed asymptomatic infection

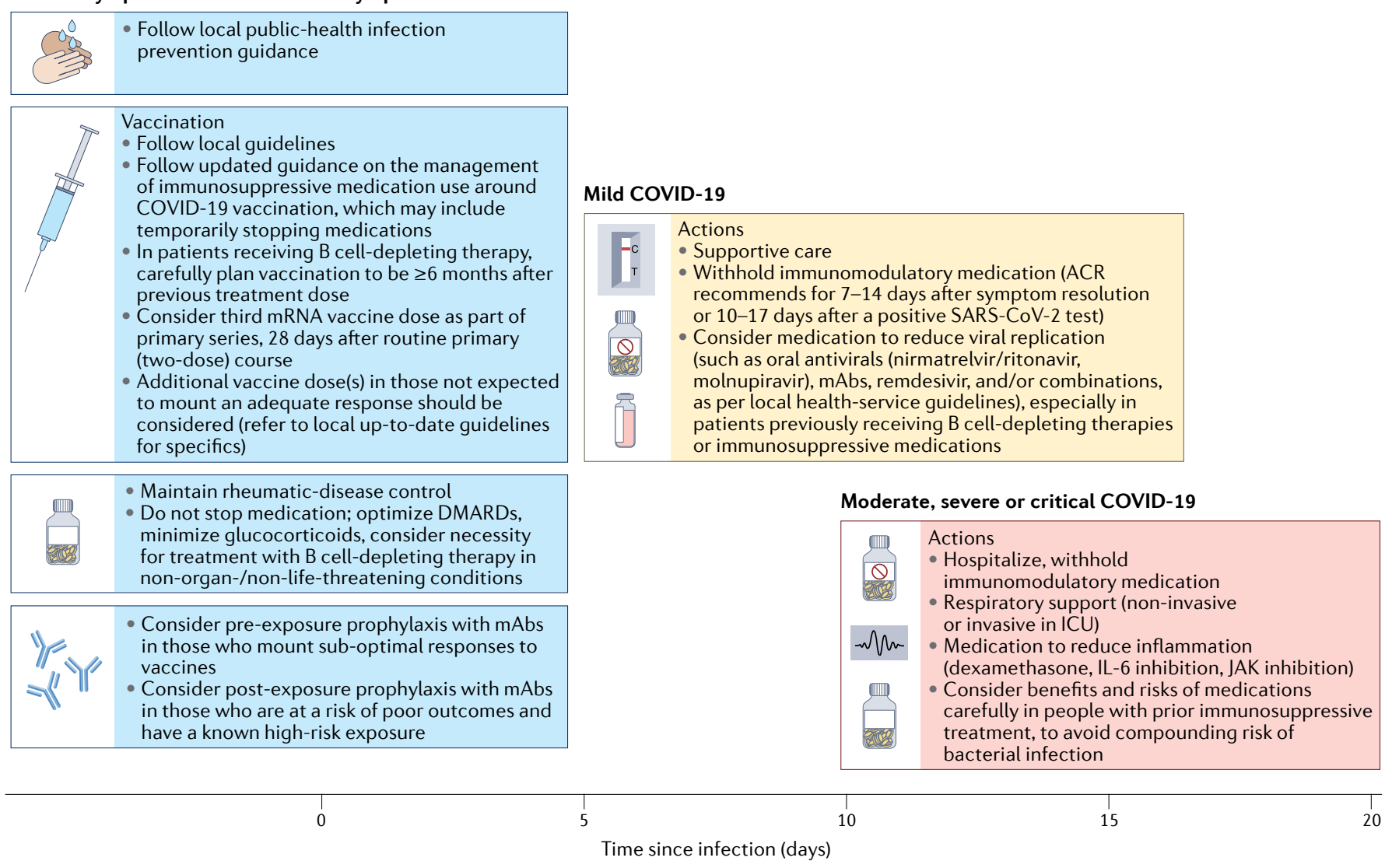

Fig. 1 SARS-CoV-2 pre-infection and post-infection considerations for people with rheumatic disease. Actions for people with rheumatic disease to take while living in an area with community transmission of SARS-CoV-2, dependent on whether they are uninfected, or have confirmed asymptomatic or symptomatic (mild, moderate, severe or critical) COVID-19.

nirmatrelvir (Paxlovid). Specific data in immunocompromised individuals are lacking, but use of these drugs in patients who are at a high risk is recommended ${ }^{58,68}$.

The US Food and Drug Administration has expanded the Emergency Use Authorization for anti-SARS$\mathrm{CoV}-2$ monoclonal-antibody therapy as post-exposure prophylaxis (PEP) for high-risk patients on the basis of the results of two randomized controlled trials ${ }^{69}$. Individuals with rheumatic diseases who are not fully vaccinated or who are at a risk of an inadequate immune response to vaccination should be considered for PEP. Specific choices of drug combinations (such as sotrovimab, bamlanivimab plus etesevimab or casirivimab plus imdevimab) should be made on the basis of regional SARS-CoV-2 susceptibility patterns, which change over time. PEP should be administered within 7 days of high-risk exposure. In regions where monoclonal-antibody therapy is available, patients should be strongly counselled to inform their health-care teams about high-risk exposures as soon as possible, so that appropriate treatment can be arranged.

Studies evaluating the use of pre-exposure prophylaxis with monoclonal antibodies against SARS-CoV-2 in immunocompromised individuals are ongoing and are of particular interest in relation to those with an inadequate vaccine response (for example, NCT04625725).
Management of hospitalized patients. The management of individuals who are hospitalized with COVID-19 is currently based on the severity of illness, particularly with regard to oxygen requirements and ventilatory status $^{70}$. For example, those who are hospitalized but who do not require supplemental oxygen might not need any specific therapy, whereas those who have progressed to requiring low-flow supplemental oxygen should receive remdesivir, dexamethasone or a combination of these two medications ${ }^{70}$. Those with more-severe disease should receive dexamethasone and, in some instances, additional immunomodulation with IL-6 inhibitors or JAK inhibitors, as described below. Although treatment guidelines such as those put forth by the $\mathrm{NIH}^{58}$ should generally be applied to individuals with rheumatic diseases, customization may be required, for example, with the use of anti-SARS-CoV-2 monoclonal antibodies in hospitalized patients with persistent viral replication, or avoidance of IL-6 inhibitors or JAK inhibitors in those who are already heavily immunosuppressed.

Remdesivir, an inhibitor of viral RNA-dependent RNA polymerases, reduces disease progression in hospitalized patients with COVID-19 who require supplemental oxygen, according to results from the ACTT-1 trial, but not the SOLIDARITY trial ${ }^{71,72}$. Although remdesivir is not recommended for those requiring invasive 
mechanical ventilation, as viral replication is not considered to be the main factor in this later phase of illness, for hospitalized patients with rheumatic disease who require oxygen therapy, remdesivir should be considered ${ }^{73}$.

For patients who have progressed to the more severe, inflammatory phase of COVID-19, specific management focuses on dampening the pathological immune response. Currently, dexamethasone treatment is associated with survival benefits in hospitalized patients who require supplemental oxygen, particularly those with severe disease who have progressed to invasive mechanical ventilation ${ }^{43}$. Results suggest that combination immunosuppressive therapy lessens disease progression and might reduce mortality in certain subsets of patients. For example, compared with glucocorticoid therapy alone, addition of IL- 6 inhibitors such as tocilizumab or sarilumab reduced mortality among patients who were experiencing rapid respiratory decompensation in the
REMAP-CAP study ${ }^{69}$ and those with high concentrations of C-reactive protein and oxygen requirements in the RECOVERY study ${ }^{74,75}$. Similarly, data suggest that addition of a JAK inhibitor, such as baricitinib or tofacitinib, to corticosteroid therapy improves outcomes for hospitalized patients with COVID-19 requiring oxygen support $^{48,49}$. IL-1 inhibition might also have a role in some hypoxaemic hospitalized patients, as results from one randomized controlled trial of anakinra demonstrated reduction of disease progression and mortality among patients with plasma concentrations of the inflammatory marker soluble urokinase plasminogen activator receptor $\geq 6 \mathrm{ng} \mathrm{ml}^{-1}\left(\mathrm{REF}^{76}\right)$.

Monoclonal antibodies against SARS-CoV-2 might have a role in the treatment of hospitalized patients with COVID-19. A preliminary report from the RECOVERY study identified that among individuals who were seronegative at baseline for SARS-CoV-2, hospital mortality was

Table 3 | Therapeutics for COVID-19 currently licensed or with emergency use authorization

\begin{tabular}{|c|c|c|c|}
\hline Drug & Action & $\begin{array}{l}\text { Indications for use in people } \\
\text { with rheumatic disease }\end{array}$ & $\begin{array}{l}\text { Considerations in people } \\
\text { with rheumatic disease }\end{array}$ \\
\hline \multicolumn{4}{|l|}{ Direct antivirals } \\
\hline \multirow[t]{3}{*}{$\begin{array}{l}\text { Casirivimab plus } \\
\text { imdevimab }\end{array}$} & \multirow[t]{3}{*}{$\begin{array}{l}\text { Anti-SARS-CoV- } 2 \text { mAbs that bind to } \\
\text { non-overlapping epitopes of the spike } \\
\text { protein receptor binding domain }\end{array}$} & $\begin{array}{l}\text { Treatment of non-hospitalized patients with } \\
\text { mild or moderate COVID-19 who are at a risk } \\
\text { of progression }\end{array}$ & \multirow{2}{*}{$\begin{array}{l}\text { Treatment of high-risk hospitalized } \\
\text { patients with COVID-19 who } \\
\text { have a poor humoral response to } \\
\text { SARS-CoV-2 should be considered } \\
\text { when mAbs are available } \\
\text { (compassionate use) }\end{array}$} \\
\hline & & \multirow{2}{*}{$\begin{array}{l}\text { Post-exposure prophylaxis in non-hospitalized } \\
\text { patients who are unvaccinated or vaccinated } \\
\text { but not expected to mount an adequate } \\
\text { immune response }\end{array}$} & \\
\hline & & & \multirow{4}{*}{$\begin{array}{l}\text { Patients with rheumatic disease } \\
\text { should be counselled to alert their } \\
\text { clinicians about SARS-CoV- } 2 \text { infection } \\
\text { or exposure as early as possible, so } \\
\text { that mAb therapy can be arranged }\end{array}$} \\
\hline Sotrovimab & $\begin{array}{l}\text { Anti-SARS-CoV- } 2 \mathrm{mAb} \text {, targets an } \\
\text { epitope in the receptor binding domain } \\
\text { of the spike protein that is conserved } \\
\text { between SARS-CoV and SARS-CoV-2 }\end{array}$ & $\begin{array}{l}\text { Treatment of non-hospitalized patients with } \\
\text { mild or moderate COVID-19 who are at a risk } \\
\text { of progression }\end{array}$ & \\
\hline \multirow[t]{2}{*}{$\begin{array}{l}\text { Bamlanivimab } \\
\text { plus etesevimab }\end{array}$} & \multirow{2}{*}{$\begin{array}{l}\text { Anti-SARS-CoV- } 2 \text { mAbs that bind to } \\
\text { different but overlapping epitopes } \\
\text { in the spike protein receptor binding } \\
\text { domain }\end{array}$} & $\begin{array}{l}\text { Treatment of non-hospitalized patients with } \\
\text { mild or moderate COVID-19 who are at a risk } \\
\text { of progression }\end{array}$ & \\
\hline & & $\begin{array}{l}\text { Post-exposure prophylaxis in non-hospitalized } \\
\text { patients who are unvaccinated or vaccinated, } \\
\text { but not expected to mount an adequate } \\
\text { immune response }\end{array}$ & \\
\hline $\begin{array}{l}\text { Tixagevimab } \\
\text { plus cilgavimab }\end{array}$ & $\begin{array}{l}\text { Anti-SARS-CoV-2 mAbs that bind to } \\
\text { epitopes in the spike protein receptor } \\
\text { binding domain }\end{array}$ & $\begin{array}{l}\text { Pre-exposure prophylaxis of COVID-19 } \\
\text { in adults and children } \geq 12 \text { years old }\end{array}$ & $\begin{array}{l}\text { This treatment should be considered in } \\
\text { those who have sub-optimal responses } \\
\text { to vaccines (such as patients treated } \\
\text { with B cell-depleting therapies) }\end{array}$ \\
\hline Remdesivir & RNA-polymerase inhibitor & Hospitalized with moderate disease only & $\begin{array}{l}\text { Consider for patients who require } \\
\text { low-flow supplemental oxygen, } \\
\text { but not for those with more severe } \\
\text { disease requiring invasive mechanical } \\
\text { ventilation }\end{array}$ \\
\hline \multicolumn{4}{|c|}{ Anti-inflammatories } \\
\hline Dexamethasone & Glucocorticoid & Hospitalized, requiring supplemental oxygen & \multirow{2}{*}{$\begin{array}{l}\text { Dexamethasone can be used in most } \\
\text { people with rheumatic disease and } \\
\text { COVID-19, even those on other } \\
\text { immunosuppressive therapies }\end{array}$} \\
\hline Baricitinib & Janus kinase inhibitor & $\begin{array}{l}\text { Hospitalized, with rapidly increasing oxygen } \\
\text { needs and systemic inflammation }\end{array}$ & \\
\hline Tofacitinib & Janus kinase inhibitor & $\begin{array}{l}\text { Hospitalized, with rapidly increasing oxygen } \\
\text { needs and systemic inflammation }\end{array}$ & \multirow{3}{*}{$\begin{array}{l}\text { Addition of a second } \\
\text { immunomodulator to dexamethasone } \\
\text { for COVID-19 treatment should } \\
\text { be considered on a case-by-case } \\
\text { basis, especially in patients who are } \\
\text { immunosuppressed with other drugs } \\
\text { for their rheumatic disease }\end{array}$} \\
\hline Tocilizumab & IL-6 receptor inhibitor & $\begin{array}{l}\text { Hospitalized, with rapidly increasing oxygen } \\
\text { needs and systemic inflammation }\end{array}$ & \\
\hline Sarilumab & IL-6 receptor inhibitor & $\begin{array}{l}\text { Hospitalized, with rapidly increasing oxygen } \\
\text { needs and systemic inflammation }\end{array}$ & \\
\hline
\end{tabular}




\title{
Box 1 NIH clinical spectrum of SARS-CoV-2 infection ${ }^{14}$
}

\section{Asymptomatic or pre-symptomatic infection \\ - Individuals who test positive for SARS-CoV-2 using a virological test (that is, a nucleic- acid amplification test or an antigen test) but who have no symptoms that are consistent with COVID-19.}

\author{
Mild illness \\ - Individuals who have any of the various signs and symptoms of COVID-19 (such as \\ fever, cough, sore throat, malaise, headache, muscle pain, nausea, vomiting, diarrhoea, \\ loss of taste and smell) but who do not have shortness of breath, dyspnoea, or abnormal \\ chest imaging.
}

\section{Moderate illness}

- Individuals who show evidence of lower-respiratory disease during clinical assessment or imaging and who have an oxygen saturation $\left(\mathrm{SpO}_{2}\right) \geq 94 \%$ when breathing room air.

\section{Severe illness}

- Individuals who have $\mathrm{SpO}_{2}<94 \%$ when breathing room air, a ratio of arterial partial pressure of oxygen to fraction of inspired oxygen $\left(\mathrm{PaO}_{2} / \mathrm{FiO}_{2}\right)<300 \mathrm{mmHg}$, a respiratory rate $>30$ breaths per min, or lung infiltrates $>50 \%$.

\section{Critical illness}

- Individuals who have respiratory failure, septic shock and/or multiple-organ dysfunction.

Vaccine efficacy

A measure of proportional reduction in cases using a specific outcome (infection or hospitalization) within well-defined conditions among vaccinated individuals, such as those within clinical trials.

\section{Seropositivity}

Assessment of whether anti-spike antibodies

are present or not, versus the levels of antibodies (see antibody titres/levels).

\section{Antibody titre}

All antibodies that bind to the target antigen (for SARS-CoV-2, the whole spike protein or the receptor binding domain of the spike protein) expressed as a titre (the dilution of plasma or sera where anti-spike antibodies become undetectable).

\section{Neutralization titres} Ability of antibodies to block in vitro binding of receptor binding domain of spike protein to angiotensinconverting enzyme 2 , measured using target cells that form plaques after virus infection, which neutralizing antibodies block, and usually expressed as half-maximal neutralization titres. lower in those who received casirivimab plus imdevimab than in those who received the usual standard of care alone ${ }^{77}$. Hospitalized patients with rheumatic disease who have received BCDTs or other immunosuppression that severely impairs their humoral immune responses are expected to benefit from this therapy.

In summary, management of COVID-19 in people with rheumatic disease should generally follow guidance for the wider local population. Individualized treatment decisions, guided by rheumatological consultation, might be desirable for patients who already receive immunosuppressive treatment, as combining immunosuppressive drugs could increase the risk of adverse events (particularly infections) ${ }^{55}$. For example, for a patient receiving high-dose glucocorticoids and cyclophosphamide at the time of COVID-19 hospitalization, further immunosuppression with IL-6 inhibition, JAK inhibition or IL-1 inhibition could increase the risk of serious hospital-acquired infections to a level that exceeded any likely COVID-19-related benefits. By contrast, a patient using long-term, low-dose methotrexate who develops severe COVID-19 might be advised to temporarily discontinue the methotrexate, and to receive treatment with dexamethasone combined with IL-6 inhibition or JAK inhibition, which have demonstrated benefits for serious COVID-19. In addition, because the viral replication and inflammatory stages of COVID-19 can overlap in patients with an altered or compromised immune system, concomitant antiviral therapies, such as monoclonal antibodies directed against SARS-CoV-2, should be considered when the patient has not produced neutralizing antibodies to the virus, even as the risks of increasing immunosuppression are being evaluated.

\section{COVID-19 vaccination considerations}

As mentioned in the Introduction, the rapid development of vaccines for COVID-19 is one of the greatest achievements of modern medical science. There are six COVID-19 vaccines in widespread use, including mRNA vaccines (BNT162b2 (Pfizer-BioNTech) and mRNA-1273 (Moderna)), viral-vector vaccines (ChAdOx1 (AstraZeneca), Ad26.COV2.S (Johnson \& Johnson) and Gam-COVID-Vac (also known as Sputnik V)), killed-virus vaccines (CoronaVac (Sinovac) and Sinopharm). The protein-subunit vaccine NVX-CoV2373 (Novavax) is also likely to have widespread use, but its approval has lagged behind that of the others. The construction of these vaccines is discussed elsewhere ${ }^{1}$, and the immune response that provides protection is outlined in FIG. 2. All of these vaccines lead to the production of neutralizing antibodies and have efficacy against symptomatic SARS-CoV-2 infection in the general population ${ }^{78}$. In published real-world effectiveness studies of vaccination programmes, viral-vector vaccines and mRNA vaccines provide similar (very good) levels of protection ${ }^{79}$. Waning immunity following an initial series of vaccinations is an issue that is being addressed with additional doses of vaccine ${ }^{80,81}$. Data on vaccine efficacy against SARS-CoV-2 variants will lag behind the spread of virus variants. Despite these considerations, everyone should be strongly supported to receive COVID-19 vaccination.

\section{Immunogenicity: antibody and neutralization titres.} SARS-CoV-2 vaccination in immunocompetent hosts generates high titres of antibodies against the viral spike protein, with virtually all vaccinated individuals achieving seropositivity ${ }^{82-85}$. Most people with immune or inflammatory rheumatic disease also generate antibody responses after vaccination, although lower antibody titres might be produced than in the wider population ${ }^{4,86-98}$. In a study conducted in Israel, rates of spike-protein seropositivity following mRNA vaccination in people with rheumatic disease were $86 \%$, compared with $100 \%$ in a healthy population ${ }^{88}$. Another large Israeli cohort of people with rheumatic disease also had an $86 \%$ seroconversion rate after mRNA vaccination ${ }^{95}$. In a German cohort, $94 \%$ of the participants with rheumatic disease were seropositive post-vaccination, including 90.5\% with neutralizing responses ${ }^{90}$. These data provide reassurance that the majority of people with rheumatic disease respond to COVID-19 vaccination with an antibody response. However, the data on post-vaccination antibody titres in people with rheumatic disease compared with the general population warrant further scrutiny. In a small study conducted in Germany, antibody titres were $24 \%$ lower in people with rheumatic disease than in healthy individuals ${ }^{86}$. In the US COVaRiPAD study, people with rheumatic disease had, on average, postvaccination antibody titres that were one-third of those in immunocompetent participants, and approximately $85 \%$ of those in the rheumatic-disease cohort generated antibody responses ${ }^{4}$. Neutralization titres of antibodies to the common variant (D614G) of the spike protein generally mirror total anti-spike antibody titres closely; thus, neutralization titres also tend to be lower in people with rheumatic disease than in the general population ${ }^{4,86,90}$. Overall, these data suggest that most people with rheumatic disease will have antibody responses to SARS-CoV-2 vaccination that are similar to those of 
the wider population, with antibody titres that are protective, at least in the short term. However, people with rheumatic disease can differ from each other in terms of their intrinsic alterations of immune functions and use of medications that might affect vaccination responses.

Evidence suggests that some treatments for rheumatic disease can reduce, or even prevent, antibody response to SARS-CoV-2 vaccination. The therapies of most concern involve BCDTs, glucocorticoids, mycophenolate and JAK inhibitors (FIG. 2). In a study conducted in Israel, 22 of the 47 people receiving the BCDT rituximab did not mount an antibody response, which represented 59\% of all non-responders in the cohort ${ }^{95}$. In another study from Israel, the lowest seropositivity rates occurred in people who had received BCDT, with $39 \%$ seropositivity overall in this group. Of the $39 \%$ who became seropositive, $20 \%$ of this group who received BCDT within 6 months prior to vaccination achieved seropositivity. At 1 year following receipt of BCDT, nearly $50 \%$ of this group were seropositive ${ }^{88}$. The association of BCDT with reduction in antibody response has been observed in patients with rheumatic disease $\mathrm{A}^{4,88,92,95-97,99-102}$ and kidney transplantation ${ }^{103}$. The effect of BCDT on vaccine-induced humoral responses is not surprising given the central role in these responses of $\mathrm{B}$ cell activation and differentiation to antibody-secreting cells. Notably, BCDT also affects immune responses to influenza vaccination and pneumococcal vaccination

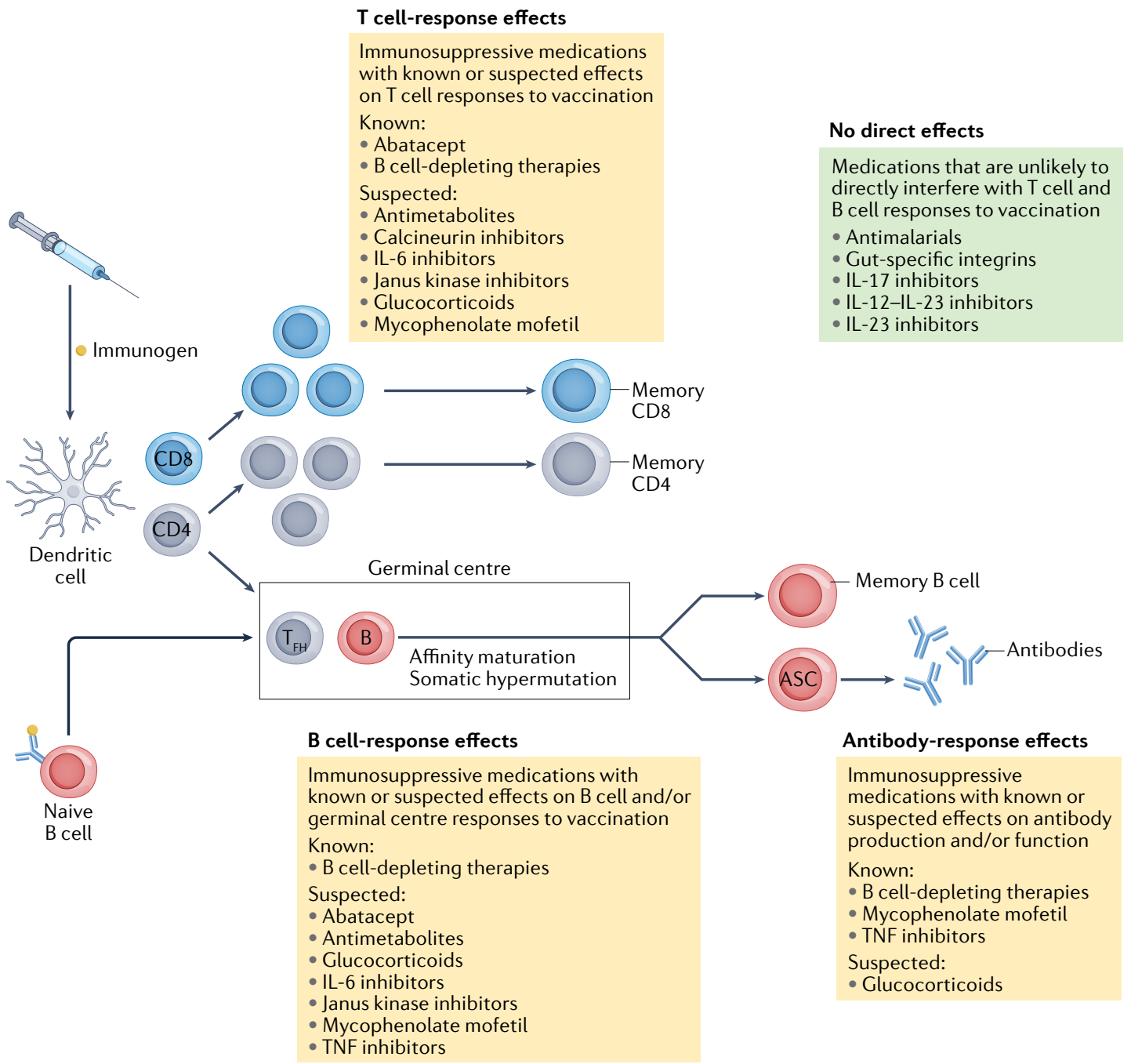

Fig. 2 | Vaccine-induced immune responses and potential effects of immunosuppression. Protective responses generated by vaccination require sequential activation of several immune cells. Following delivery of the immunogen by vaccination, dendritic cells activate $\mathrm{CD} 4^{+} \mathrm{T}$ cells, which polarize into a variety of helper $\mathrm{T}$ cell subsets, including $\mathrm{T}$ follicular helper $\left(T_{F H}\right)$ cells. Soluble immunogens also activate immunogen-specific naive B cells, which encounter $T_{F H}$ cells. This interaction is a critical step in the induction of T cell-dependent B cell responses to initiate the germinal centre response, which generates a pool of mature B cells harbouring a diverse array of B cell receptors with high affinity for the immunogen. These mature B cells can further differentiate into memory B cells or antibody-secreting cells (ASCs). The diversification of the $B$ cell receptor repertoire (and thus antibody secretion) is critical for broad coverage of the numerous epitopes the immunogen contains, and for neutralization of virus variants. Immunosuppressive medications influence $T$ and $B$ cell function, some more specifically than others. Immunosuppressives with known or suspected effects on T cell and B cell responses to SARS-CoV-2 vaccination are shown. Medications that affect the immune system but are unlikely to directly interfere with T cell and B cell responses to vaccination because of their mechanisms of action are also shown. 
in patients with $\mathrm{RA}^{104,105}$. The presence of peripheral B cells at $>10$ cells per microlitre around 6 months after treatment with BCDT seems to be a reliable indication that seroconversion will occur following SARS-CoV-2 vaccination in people with RA or ANCA-associated vasculitis $^{4,88,106-109}$.

The use of mycophenolate (including mycophenolate mofetil and mycophenolic acid) is associated with substantial impairment of humoral immunity following SARS-CoV-2 vaccination. Mycophenolate inhibits inosine monophosphate dehydrogenase, which impairs proliferation of lymphocytes and consequently inhibits cell-mediated and humoral immune responses. In the Johns Hopkins cohort, the seroconversion rate following two vaccine doses in patients with RMDs who were treated with mycophenolate was $73 \%$, and median antibody titres were lower than in patients treated with TNF inhibitors $\left(8 \mathrm{U} \mathrm{ml}^{-1} \text { versus }>250 \mathrm{U} \mathrm{ml}^{-1}\right)^{97}$. Similarly, the seroconversion rate was $64 \%$ in individuals treated with mycophenolate mofetil in an Israeli cohort ${ }^{88}$. Mycophenolate is also associated with detrimental effects on antibody titres in kidney-transplant recipients, among whom seroconversion rates are as low as $29 \%{ }^{110}$. In recipients of solid-organ transplant with immunosuppression, a third SARS-CoV-2 mRNA vaccine dose can achieve 55\% seroconversion, compared with $18 \%$ after two vaccine doses ${ }^{111}$. Results suggest that withholding mycophenolate before and/or after SARS-CoV-2 vaccination has beneficial effects on the probability of antibody response, and on antibody titres ${ }^{112}$. Although specific data on the outcomes of this strategy in people with rheumatic disease are not yet available, the ACR has already recommended that a third mRNA vaccine dose should be administered to all patients with autoimmune and inflammatory rheumatic disease $\geq 28$ days after completing the second dose of the primary vaccination course, unless they are on hydroxychloroquine monotherapy ${ }^{113}$. Vaccination strategies are likely to continue to be updated as new data become available.

Data consistently indicate that immunogenicity following SARS-CoV-2 vaccination is affected in people who are treated with glucocorticoids ${ }^{4,88,91,97}$ (FIG. 2). In US (Johns Hopkins) and Dutch cohorts, approximately $80 \%$ of people with rheumatic disease who received glucocorticoids seroconverted ${ }^{91,97}$, and this value was $66 \%$ in an Israeli cohort ${ }^{88}$. In the US COVaRiPAD study, antibody titres in people with rheumatic disease were lower than those in people who were considered immunocompetent (only $65 \%$ of people with rheumatic disease had titres consistent with seropositivity), and titres were lower still in people who received low-dose prednisone $(<7.5 \mathrm{mg} \text { per day })^{4}$. Notably, confounding by additional immunosuppression (especially BCDT and mycophenolate use) was observed in the Johns Hopkins cohort, as prednisone users with reduced antibody titres were generally also receiving these medications ${ }^{97}$. Studies with larger cohorts will be required to further explore the impact of glucocorticoid use and use of combined immunosuppressive therapies on immunogenicity following SARS-CoV-2 vaccination.

Several classes of medication seem to result in modest reductions in antibody titres, including TNF inhibitors, antimetabolites (such as methotrexate, sulfasalazine and leflunomide) and JAK inhibitors ${ }^{4,87,88,90,91,95,97,98}$ (FIG. 2). In the SAGA cohort, seroconversion rates were lower $(62 \%)$ in people with rheumatic disease who received methotrexate than in immunocompetent controls $(98 \%$ seroconversion) or in people with rheumatic disease who were treated with other agents ( $92 \%$ seroconversion $)^{87}$. Methotrexate was associated with a similar effect in a UK cohort of patients with psoriasis ${ }^{98}$. Despite relatively good seroconversion rates in patients receiving TNF inhibitors, preliminary data from the COVaRiPAD group showed that TNF inhibitor monotherapy is associated with lower neutralization titres against the B.1.617.2 (delta) variant than those in immunocompetent and otherwise immunosuppressed participants ${ }^{114}$. For some classes of immunosuppression, such as $\mathrm{T}$ cell co-stimulation blockers, IL-12-IL-23 inhibitors, IL-17 inhibitors and IL-1 inhibitors, little is known about the effects on immunogenicity. Some preliminary data from studies with small sample sizes suggest that treatment with IL-12-IL-23 inhibitors ${ }^{4}$, IL-17 inhibitors ${ }^{88}$ or IL-1 inhibitors ${ }^{115}$ does not have an appreciable effect on antibody titres.

To date, a handful of studies have examined immunogenicity following a first dose of mRNA-based SARSCoV-2 vaccine ${ }^{86,90,91,116}$. The results indicate that seroconversion is delayed in individuals with autoimmune diseases who receive immunosuppressive therapies ${ }^{90,91}$, and in recipients of solid-organ transplants ${ }^{117}$. In patients with RMDs, the lowest antibody titres after one vaccine dose are found in those who receive BCDT or mycophenolate ${ }^{116}$, as well as in those treated with methotrexate (who can achieve reasonable antibody levels following a second vaccine dose $)^{91}$. Delaying administration of the second dose of vaccine might be riskier for those with rheumatic disease receiving immunosuppressive therapy than for those who receive their second dose as recommended, as this strategy could result in delay of seroconversion with no demonstrated benefit to the eventual rate of seroconversion.

Although most studies have focused on the effects that immunosuppression in people with rheumatic disease has on vaccine immunogenicity, few data exist in relation to whether having a rheumatic disease is in itself a risk factor for reduced immunogenicity. Analyses using a German cohort suggested that having a rheumatic disease was independently associated with reduced antibody responses, as anti-spike antibody titres were lower in participants with untreated immune or inflammatory rheumatic disease than in people who were considered to be immunocompetent, even after controlling for age, sex and time from first vaccination date $e^{90}$. Nevertheless, greater reductions in antibody titres occurred in this cohort in people who were treated with bDMARDs, targeted synthetic DMARDs and conventional synthetic DMARDs than in those receiving other therapies, supporting the association of immunosuppression with antibody responses induced by SARS-CoV-2 vaccination ${ }^{90}$. Overall, it seems clear that the development of specific vaccination strategies for patients with rheumatic disease, taking therapy use into consideration, should be a key focus for future research, 
to ensure that data-informed vaccination approaches are available.

Immunogenicity: cell-mediated immunity. The data relating to cell-mediated responses to SARS-CoV-2 vaccination are limited. Results from a study involving 82 individuals with immune-mediated inflammatory disease (and 208 healthy individuals) showed that methotrexate use did not affect increases in spike-specific $\mathrm{B}$ cells, $\mathrm{CD} 4^{+} \mathrm{T}$ cells and most $\mathrm{CD} 8^{+} \mathrm{T}$ cell subsets after vaccination with the BNT162b2 mRNA vaccine ${ }^{87}$. This finding suggests that methotrexate monotherapy has minimal impact on most cellular responses following vaccination; however, total numbers of activated $\mathrm{CD}^{+} \mathrm{T}$ cells did not increase in methotrexate-treated individuals with rheumatic disease in response to vaccination.

Several studies have produced data on $\mathrm{T}$ cell responses in relation to $\mathrm{BCDT}^{92,101,118}$. In a small study that included people with RA or ANCA-associated vasculitis treated with rituximab, concentrations of spike-specific $\mathrm{B}$ cells, total $\mathrm{T}$ follicular helper cells and $\mathrm{CD} 4^{+}$and $\mathrm{CD}^{+} \mathrm{T}$ cells were lower in individuals without seroconversion than in those with seroconversion ${ }^{118}$ (FIG. 2). Additionally, spike-specific CD4 ${ }^{+} \mathrm{T}$ cells secreted less IFN $\gamma$ upon peptide stimulation in individuals without seroconversion, suggesting that the absence of B cells attenuates T cell activation, possibly through inadequate co-stimulation. Results from two larger studies demonstrated that although individuals who do not generate humoral responses in the context of BCDT can generate spike-specific $\mathrm{CD} 4^{+} \mathrm{T}$ cells, these cells have impaired function, as assessed by IFN $\gamma$ release ${ }^{92,101}$. The clinical import of these findings is not known, but they highlight the differential effects that immunosuppressive medications can have on cellular responses.

Breakthrough infections in individuals with rheumatic disease. Although numerous groups have published immunogenicity data assessing surrogates of protection, ultimately vaccine effectiveness data will provide the final verdict on the effect of immunosuppression on SARS$\mathrm{CoV}-2$ vaccination. Results from a study conducted in Israel revealed that vaccine effectiveness for prevention of symptomatic COVID-19 in those on immunosuppression was $71 \%$ compared with $94 \%$ in immunocompetent individuals ${ }^{119}$. Similarly, vaccine effectiveness for avoiding hospitalization was lower in immunosuppressed than in immunocompetent individuals $(62.9 \%$ versus $91.3 \%)^{120}$. Indeed, individuals with immunosuppression represented almost half of the hospitalized breakthrough infections in studies in Israel and the USA ${ }^{120,121}$ and four out of 14 patients with breakthrough severe or critical illness in another US study ${ }^{122}$. Among 16 individuals with breakthrough COVID-19 in yet another US study, only one was not receiving any DMARD or glucocorticoid at the time of vaccination ${ }^{123}$. Nevertheless, data from the EULAR COVID-19 registry and COVAX registry suggest that breakthrough rates are low $(<1 \%)$ in fully vaccinated individuals with inflammatory $\mathrm{RMDs}^{124}$. Notably, the observations described herein were largely made prior to the outbreak of the delta and omicron variants of SARS-CoV-2, which might result in alteration of the association of particular immunosuppressive medications with breakthrough infections.

Adverse events after vaccination and flares of rheumatic disease. Although the data relating to immunogenicity in people with rheumatic disease are important for understanding which patients might have a suboptimal vaccine response, all patients are interested in the risk of adverse reactions. Comparative data on the rate of adverse events following vaccination in people with rheumatic disease are scarce, but results from studies conducted pre-pandemic suggest similar rates of local and systemic reactions in people with SLE who receive placebo or live herpes zoster vaccine (although the vaccine was associated with higher rates of injection-site reactions) $)^{125-127}$

mRNA vaccination is associated with a theoretical risk of disease flares, particularly in patients with SLE. mRNA is a trigger of interferon responses via activation of pattern-recognition receptors such as Toll-like receptors or the intracellular sensors stimulator of interferon genes (STING) and retinoic acid-inducible gene I (RIG-I). Systemic concentrations of type I interferon increase in response to viral infections (including SARS-CoV-2 infection) $)^{128}$, and are associated with mRNA vaccination ${ }^{129}$. Because concentrations of type I interferon are elevated in diseases such as SLE $^{130}$ (in which inhibition of type I interferon is a therapeutic target $)^{131,132}$, there is a risk that vaccination-induced elevation of type I interferon could cause flares of rheumatic disease. Notably, however, the introduction of modified nucleosides (such as pseudouridine) into current mRNA vaccines considerably reduces recognition by pattern-recognition receptors ${ }^{133}$. Specifically in relation to vaccination against SARS-CoV-2, self-reported flare rates among 1,101 patients with rheumatic disease who received mRNA-based vaccines were high (17\%), with $23 \%$ of the flares occurring only after the first dose, $43 \%$ only after the second dose and $33 \%$ after both doses $^{134}$. Similarly, among 1,377 patients with RMDs who received two doses of mRNA-based SARS-CoV-2 vaccines, $11 \%$ reported flares that required treatment; factors associated with these flares included prior SARS-CoV-2 infection, previous flare (within 6 months of vaccination) and use of combination immunomodulatory therapy ${ }^{135}$. In SLE, type I interferon responses strongly associate with disease activity ${ }^{136}$, and in the vaccination against COVID in systemic lupus study ${ }^{137}$, only 21 of 696 individuals (3\%) with SLE who received any SARS-CoV-2 vaccine had a medically confirmed flare, and SLE disease-activity scores were unchanged following vaccination ${ }^{94}$. No notable flares of rheumatic disease were identified in four other studies that between them included over 6,000 people with rheumatic disease who received SARS-CoV-2 vaccines ${ }^{86,88,95,138}$.

Vaccinations: practical considerations. Data relating to vaccination and rheumatic disease are being generated at a considerable rate, and recommendations for clinical practice will need to be regularly updated. The ACR has collated comprehensive, data-informed 
vaccination recommendations that are revised regularly ${ }^{139}$. Practitioners must also review country-specific recommendations regarding vaccination.

\section{Conclusions}

The rapid response of the international rheumatology community to the COVID-19 pandemic has provided some answers to pressing clinical questions for people with rheumatic disease. Available evidence suggests that this group has a slightly higher risk of infection with SARS-CoV-2 and of poor medical outcomes from COVID-19 than the general population. Some of the risk of poor outcomes is associated with the burden of comorbidities in this group, but there also seems to be risk associated with active disease, and with the use of glucocorticoids and DMARDs. Although guidance is now available in relation to effective therapies for COVID-19 in the general population, specific data for people with rheumatic disease are required. Further work is also needed to inform vaccination strategies for people receiving medications that are associated with reduced vaccine responses, such as rituximab, and to provide clarification about the need to withhold common medications post-vaccination ${ }^{113}$. Numerous other knowledge gaps also remain, including the effects of specific rheumatic diseases on vaccine effectiveness, the usefulness of additional doses of vaccine and the relative importance of humoral and cell-mediated immunity in the prevention of severe outcomes. Alteration of infection dynamics and COVID-19 severity as variants emerge also creates uncertainty, as variants that increase transmissibility, pathogenicity and immune evasion might be of particular concern to people with rheumatic disease, especially those undergoing immunosuppressive therapy ${ }^{140}$. Despite these concerns, the research success in promptly addressing many key concerns relating to SARS-CoV-2 and rheumatic disease is impressive ${ }^{141}$. The rheumatology research community will need to maintain this momentum, to provide timely and informative data that can help to optimize the care of people with rheumatic disease in this evolving pandemic.

Published online 25 February 2022
1. Krammer, F. SARS-CoV-2 vaccines in development. Nature 586, 516-527 (2020).

2. Maddur, M. S., Vani, J., Lacroix-Desmazes, S Kaveri, S. \& Bayry, J. Autoimmunity as a predisposition for infectious diseases. PLoS Pathog. 6, e1001077 (2010).

3. Sattui, S. E. et al. Early experience of COVID-19 vaccination in adults with systemic rheumatic diseases: results from the COVID-19 Global Rheumatology Alliance Vaccine Survey. RMD Open 7 , e001814 (2021).

4. Deepak, P. et al. Effect of immunosuppression on the immunogenicity of mRNA vaccines to SARS-CoV-2: a prospective cohort study. Ann. Intern. Med. 174 1572-1585 (2021)

5. Voysey, M. et al. Safety and efficacy of the ChAdOx 1 nCoV-19 vaccine (AZD 1222) against SARS-CoV-2: an interim analysis of four randomised controlled trials in Brazil, South Africa, and the UK. Lancet 397, 99-111 (2021).

6. Bohn, M. K. et al. Pathophysiology of COVID-19: mechanisms underlying disease severity and progression. Physiology 35, 288-301 (2020).

7. Amigues, I. et al. Coronavirus disease 2019: investigational therapies in the prevention and treatment of hyperinflammation. Expert. Rev. Clin. Immunol. 16, 1185-1204 (2020).

8. Meyerowitz, E. A., Richterman, A., Gandhi, R. T. \& Sax, P. E. Transmission of SARS-CoV-2: a review of viral, host, and environmental factors. Ann. Intern. Med. 174, 69-79 (2021).

9. Davies, N. G. et al. Age-dependent effects in the transmission and control of COVID-19 epidemics. Nat. Med. 26, 1205-1211 (2020)

10. Bunyavanich, S., Do, A. $\&$ Vicencio, A. Nasal gene expression of angiotensin-converting enzyme 2 in children and adults. JAMA 323, 2427-2429 (2020).

11. Adam, D. C. et al. Clustering and superspreading potential of SARS-CoV-2 infections in Hong Kong. Nat. Med. 26, 1714-1719 (2020)

12. Wang, Y. et al. Reduction of secondary transmission of SARS-CoV-2 in households by face mask use, disinfection and social distancing: a cohort study in Beijing, China. BMJ Glob. Health 5, e002794 (2020).

13. James, A. et al. High COVID-19 attack rate among attendees at events at a church - Arkansas, March 2020. MMWR 69, 632-635 (2020).

14. Chou, R., Dana, T., Jungbauer, R., Weeks, C. \& McDonagh, M. S. Masks for prevention of respiratory virus infections, including SARS-CoV-2, in health care and community settings: a living rapid review. Ann. Intern. Med. 173, 542-555 (2020).

15. Chen, M., Wei, Y., Zhang, Q., Wan, Q. \& Chen, X. Epidemiology and clinical characteristics of COVID-19 in rheumatic diseases at a tertiary care hospital in Wuhan, China. Clin. Exp. Rheumatol. 39, 442-443 (2021).
16. Zhong, J. et al. COVID-19 in patients with rheumatic disease in Hubei province, China: a multicentre retrospective observational study. Lancet Rheumatol. 2, e557-e564 (2020).

17. Pablos, J. L. et al. Prevalence of hospital PCR confirmed COVID-19 cases in patients with chronic inflammatory and autoimmune rheumatic diseases. Ann. Rheum. Dis. 79, 1170-1173 (2020).

18. Shin, Y. H. et al. Autoimmune inflammatory rheumatic diseases and COVID-19 outcomes in South Korea: a nationwide cohort study. Lancet Rheumatol. 3, e698-e706 (2021)

19. Jung, S.-Y. et al. Effect of hydroxychloroquine preexposure on infection with SARS-CoV-2 in rheumatic disease patients: a population-based cohort study. Clin. Microbiol. Infect. 27, 611-617 (2021).

20. Salvarani, C. et al. Susceptibility to COVID-19 in patients treated with antimalarials: a populationbased study in Emilia-Romagna, Northern Italy. Arthritis Rheumatol. 73, 48-52 (2021).

21. Francesconi, P. et al. COVID-19 epidemiology in rheumatic diseases in Tuscany: a case-control study. Jt. Bone Spine 88, 105131 (2021).

22. Topless, R. K. et al. Gout, rheumatoid arthritis, and the risk of death related to coronavirus disease 2019 an analysis of the UK Biobank. ACR Open Rheumatol. 3, 333-340 (2021)

23. England, B. R. et al. Risk of COVID-19 in rheumatoid arthritis: a National Veterans Affairs matched cohort study in at-risk individuals. Arthritis Rheumatol. 73, 2179-2188 (2021).

24. Sparks, J. A. et al. Associations of baseline use of biologic or targeted synthetic DMARDs with COVID-19 severity in rheumatoid arthritis: results from the COVID-19 Global Rheumatology Alliance physician registry. Ann. Rheum. Dis. 80, 1137-1146 (2021).

25. Sattui, S. E. et al. Outcomes of COVID-19 in patients with primary systemic vasculitis or polymyalgia rheumatica from the COVID-19 Global Rheumatology Alliance physician registry: a retrospective cohort study. Lancet Rheumatol. 3, e855-e864 (2021).

26. Conway, R et al. SARS-CoV-2 infection and COVID-19 outcomes in rheumatic disease: a systematic literature review and meta-analysis. Arthritis Rheumatol. https:// doi.org/10.1002/art.42030 (2021).

27. Amigues, I. et al. Coronavirus disease 2019: investigational therapies in the prevention and treatment of hyperinflammation. Expert Rev. Clin. Immunol. 16, 1185-1204 (2020).

28. Wiersinga, W. J., Rhodes, A., Cheng, A. C., Peacock, S. J. $£$ Prescott, H. C. Pathophysiology, transmission, diagnosis, and treatment of coronavirus disease 2019 (COVID-19): a review. JAMA 324, 782-793 (2020).

29. Xiang, G. et al. Clinical risk factors for mortality of hospitalized patients with COVID-19: systematic review and meta-analysis. Ann. Palliat. Med. 10, 2723-2735 (2021).
30. Levin, A. T. et al. Assessing the age specificity of infection fatality rates for COVID-19: systematic review, meta-analysis, and public policy implications. Eur. J. Epidemiol. 35, 1123-1138 (2020)

31. Reilev, M. et al. Characteristics and predictors of hospitalization and death in the first 11122 cases with a positive RT-PCR test for SARS-CoV-2 in Denmark: a nationwide cohort. Int. J. Epidemiol. 49, 1468-1481 (2020).

32. Cordtz, R. et al. Incidence and severeness of COVID-19 hospitalisation in patients with inflammatory rheumatic disease: a nationwide cohort study from Denmark. Rheumatology 60, S159-S167 (2021).

33. Williamson, E. J. et al. Factors associated with COVID-19-related death using OpenSAFELY. Nature 584, 430-436 (2020).

34. Harrison, S. L., Fazio-Eynullayeva, E., Lane, D. A., Underhill, P. \& Lip, G. Y. H. Comorbidities associated with mortality in 31,461 adults with COVID-19 in the United States: a federated electronic medical record analysis. PLoS Med. 17, e1003321 (2020).

35. Serling-Boyd, N. et al. Coronavirus disease 2019 outcomes among patients with rheumatic diseases 6 months into the pandemic. Ann. Rheum. Dis. 80, 660-666 (2021).

36. D'Silva, K. M. et al. COVID-19 outcomes in patients with systemic autoimmune rheumatic diseases compared to the general population: a US multicenter comparative cohort study. Arthritis Rheumatol. 73, 914-920 (2021).

37. Liew, J. W. et al. The COVID-19 Global Rheumatology Alliance: evaluating the rapid design and implementation of an international registry against best practice. Rheumatology $60,353-358$ (2021).

38. Wallace, Z. S. et al. The Rheumatology Community responds to the COVID-19 pandemic: the establishment of the COVID-19 global rheumatology alliance. Rheumatology 59, 1204-1206 (2020).

39. Robinson, P. C. \& Yazdany, J. The COVID-19 Global Rheumatology Alliance: collecting data in a pandemic. Nat. Rev. Rheumatol. 16, 293-294 (2020).

40. Gianfrancesco, M. et al. Characteristics associated with hospitalisation for COVID-19 in people with rheumatic disease: data from the COVID-19 Global Rheumatology Alliance physician-reported registry. Ann. Rheum. Dis. 79, 859-866 (2020).

41. Strangfeld, A. et al. Factors associated with COVID-19related death in people with rheumatic diseases: results from the COVID-19 Global Rheumatology Alliance physician-reported registry. Ann. Rheum. Dis. 80, 930-942 (2021)

42. Schäfer, M. et al. Response to: "Correspondence on 'Factors associated with COVID-19-related death in people with rheumatic diseases: results from the COVID-19 Global Rheumatology Alliance physician reported registry'" by Mulhearn et al. Ann. Rheum. Dis. https://doi.org/10.1136/annrheumdis-2021-220134 (2021). 
43. RECOVERY Collaborative Group. et al. Dexamethasone in hospitalized patients with Covid-19. N. Engl J. Med. 384, 693-704 (2021).

44. Robinson, P. C. \& Morand, E. Divergent effects of acute versus chronic glucocorticoids in COVID-19. Lancet Rheumatol. 3, e168-e170 (2021).

45. Gianfrancesco, M. A. et al. Association of race and ethnicity with COVID-19 outcomes in rheumatic disease: data from the COVID-19 Global Rheumatology Alliance Physician Registry. Arthritis Rheumatol. 73, 374-380 (2021)

46. Webb Hooper, M., Nápoles, A. M. \& Pérez-Stable, E. J. COVID-19 and racial/ethnic disparities. JAMA 323, 2466-2467 (2020)

47. Morales, D. R. \& Ali, S. N. COVID-19 and disparities affecting ethnic minorities. Lancet 397, 1684-1685 (2021)

48. Guimarães, P. O. et al. Tofacitinib in patients hospitalized with Covid-19 pneumonia. N. Engl. J. Med. 385, 406-415 (2021).

49. Kalil, A. C. et al. Baricitinib plus remdesivir for hospitalized adults with Covid-19. N. Engl. J. Med. 384, 795-807 (2021).

50. Jones, J. M., Faruqi, A. J., Sullivan, J. K., Calabrese, C. $\&$ Calabrese, L. H. COVID-19 outcomes in patients undergoing $B$ cell depletion therapy and those with humoral immunodeficiency states: a scoping review. Pathog. Immun. 6, 76-103 (2021).

51. Bermas, B. L. et al. COVID-19 in pregnant women with rheumatic disease: data from the COVID-19 Global Rheumatology Alliance. J. Rheumatol. 49, 110-114 (2022).

52. Izadi, Z. et al. Association between tumor necrosis factor inhibitors and the risk of hospitalization or death among patients with immune-mediated inflammatory disease and COVID-19. JAMA Netw. Open 4, e2129639 (2021).

53. Robinson, P. C. et al. The potential for repurposing anti-TNF as a therapy for the treatment of COVID-19. Med 1, 90-102 (2020)

54. Landewé, R. B. et al. EULAR provisional recommendations for the management of rheumatic and musculoskeletal diseases in the context of SARS-CoV-2. Ann. Rheum. Dis. 79, 851-858 (2020).

55. Mikuls, T. R. et al. American College of Rheumatology guidance for the management of rheumatic disease in adult patients during the COVID-19 pandemic: version 3. Arthritis Rheumatol. 73, e1-e12 (2021).

56. Felten, R. et al. B-cell targeted therapy is associated with severe COVID-19 among patients with inflammatory arthritides: a 1-year multicentre study in 1116 successive patients receiving intravenous biologics. Ann. Rheum. Dis. 81, 143-145 (2021)

57. Liew, D. F. L. \& Robinson, P. C. What does endemic COVID-19 mean for the future of rituximab? Lance Rheumatol. 4, e3-e5 (2022).

58. National Institutes of Health (NIH). National Institutes of Health COVID-19 Treatment Guidelines. Therapeutic Management of Nonhospitalized Adults With COVID-19 https://www.covid 19treatmentguidelines.nih.gov/ management/clinical-management/nonhospitalizedadults--therapeutic-management/ (2021).

59. Corey, L. et al. SARS-CoV-2 variants in patients with immunosuppression. N. Engl. J. Med. 385, 562-566 (2021).

60. Choi, B. et al. Persistence and evolution of SARS-CoV-2 in an immunocompromised host. N. Engl. J. Med. 383, 2291-2293 (2020)

61. Curtis, J. R. et al. American College of Rheumatology guidance for COVID-19 vaccination in patients with rheumatic and musculoskeletal diseases: version 1. Arthritis Rheumatol. 73, 1093-1107 (2021).

62. Curtis, J. R. et al. American College of Rheumatology guidance for COVID-19 vaccination in patients with rheumatic and musculoskeletal diseases: version 2 . Arthritis Rheumatol. 73, e30-e45 (2021).

63. Long, Q.-X. et al. Antibody responses to SARS-CoV-2 in patients with COVID-19. Nat. Med. 26, 845-848 (2020).

64. Chen, P. et al. SARS-CoV-2 neutralizing antibody LY-CoV555 in outpatients with Covid-19. N. Engl. J. Med 384, 229-237 (2021)

65. Gupta, A. et al. Early treatment for Covid-19 with SARS-CoV-2 neutralizing antibody sotrovimab. N. Engl. J. Med. 385, 1941-1950 (2021).

66. Weinreich, D. M. et al. REGN-COV2, a neutralizing antibody cocktail, in outpatients with Covid-19. N. Engl. J. Med. 384, 238-251 (2021).

67. Gottlieb, R. L. et al. Effect of bamlanivimab as monotherapy or in combination with etesevimab on viral load in patients with mild to moderate COVID-19: a randomized clinical trial. JAMA 325, 632-644 (2021).

68. Painter, G. R., Natchus, M. G., Cohen, O., Holman, W. $\&$ Painter, W. P. Developing a direct acting, orally available antiviral agent in a pandemic: the evolution of molnupiravir as a potential treatment for COVID-19. Curr. Opin. Virol. 50, 17-22 (2021).

69. US Food and Drug Administration. Fact Sheet for Health Care Providers Emergency use Authorization (EUA) of Regen-Cov ${ }^{\circledR}$ [online], https://www.fda.gov/ media/145611/download (2022).

70. US National Institutes of Health. Therapeutic Management of Hospitalized Adults with COVID-19 [online], https://www.covid 19 treatmentguidelines.nih. gov/management/clinical-management/hospitalizedadults-therapeutic-management/ (2021).

71. Beigel, J. H. et al. Remdesivir for the treatment of Covid-19 - final report. N. Engl. J. Med. 383 1813-1826 (2020).

72. WHO Solidarity Trial Consortium. et al. Repurposed antiviral drugs for Covid-19 - interim WHO solidarity trial results. N. Engl. J. Med. 384, 497-511 (2021).

73. US National Institutes of Health COVID-19 Treatment Guidelines. Remdesivir [online], https:// www.covid 19treatmentguidelines.nih.gov/therapies antiviral-therapy/remdesivir/ (2021)

74. REMAP-CAP Investigators. et al. Interleukin-6 receptor antagonists in critically ill patients with Covid-19. N. Engl. J. Med. 384, 1491-1502 (2021).

75. RECOVERY Collaborative Group. Tocilizumab in patients admitted to hospital with COVID-19 (RECOVERY): a randomised, controlled, open-label, platform trial. Lancet 397, 1637-1645 (2021).

76. Kyriazopoulou, E. et al. Author correction: early treatment of COVID-19 with anakinra guided by soluble urokinase plasminogen receptor plasma levels: a double-blind, randomized controlled phase 3 trial. Nat. Med. 27, 1850 (2021)

77. RECOVERY Collaborative Group. Casirivimab and imdevimab in patients admitted to hospital with COVID-19 (RECOVERY): a randomised, controlled, open-label, platform trial. Lancet 399, 665-676 (2022).

78. Khoury, D. S. et al. Neutralizing antibody levels are highly predictive of immune protection from symptomatic SARS-CoV-2 infection. Nat. Med. 27, 1205-1211 (2021).

79. Vasileiou, E. et al. Interim findings from first-dose mass COVID-19 vaccination roll-out and COVID-19 hospital admissions in Scotland: a national prospective cohort study. Lancet 397, 1646-1657 (2021).

80. Doria-Rose, N. et al. Antibody persistence through 6 months after the second dose of mRNA- 1273 vaccine for Covid-19. N. Engl. J. Med. 384, 2259-2261 (2021).

81. Voysey, $M$ et al. Single-dose administration and the influence of the timing of the booster dose on immunogenicity and efficacy of ChAdOx 1 nCoV-19 (AZD 1222) vaccine: a pooled analysis of four randomised trials. Lancet 397, 881-891 (2021).

82. Walsh, E. E. et al. Safety and immunogenicity of two RNA-based Covid-19 vaccine candidates. N. Engl. J. Med. 383, 2439-2450 (2020).

83. Jackson, L. A. et al. An mRNA vaccine against SARS-CoV-2 - preliminary report. N. Engl. J. Med. 383, 1920-1931 (2020)

84. Anderson, E. J. et al. Safety and immunogenicity of SARS-CoV-2 mRNA-1273 vaccine in older adults. N. Engl. J. Med. 383, 2427-2438 (2020)

85. Sadoff, J. et al. Interim results of a phase 1-2a trial of Ad26.COV2.S Covid-19 vaccine. N. Engl. J. Med. 384 1824-1835 (2021).

86. Geisen, U. M. et al. Immunogenicity and safety of antiSARS-CoV-2 mRNA vaccines in patients with chronic inflammatory conditions and immunosuppressive therapy in a monocentric cohort. Ann. Rheum. Dis. 80 1306-1311 (2021).

87. Haberman, R. H. et al. Methotrexate hampers immunogenicity to BNT162b2 mRNA COVID-19 vaccine in immune-mediated inflammatory disease. Ann. Rheum. Dis. 80, 1339-1344 (2021).

88. Furer, V. et al. Immunogenicity and safety of the BNT162b2 mRNA COVID-19 vaccine in adult patients with autoimmune inflammatory rheumatic diseases and in the general population: a multicentre study. Ann. Rheum. Dis. 80, 1330-1338 (2021).

89. Veenstra, J. et al. Correspondence on "Immunogenicity and safety of anti-SARS-CoV-2 mRNA vaccines in patients with chronic inflammatory conditions and immunosuppressive therapy in a monocentric cohort". Ann. Rheum. Dis. 80, e160 (2021).
90. Simon, D. et al. SARS-CoV-2 vaccination responses in untreated, conventionally treated and anticytokine treated patients with immune-mediated inflammatory diseases. Ann. Rheum. Dis. 80, 1312-1316 (2021).

91. Boekel, L. et al. Antibody development after COVID-19 vaccination in patients with autoimmune diseases in the Netherlands: a substudy of data from two prospective cohort studies. Lancet Rheumatol. 3, e778-e788 (2021)

92. Prendecki, M. et al. Humoral and T-cell responses to SARS-CoV-2 vaccination in patients receiving immunosuppression. Ann. Rheum. Dis. $\mathbf{8 0}$ 1322-1329 (2021).

93. Ammitzbøll, C. et al. Impaired Antibody Response to the BNT $162 \mathrm{~b} 2$ messenger RNA coronavirus disease 2019 vaccine in patients with systemic lupus erythematosus and rheumatoid arthritis. ACR Open. Rheumatol. 3, 622-628 (2021).

94. Izmirly, P. M. et al. Evaluation of immune response and disease status in systemic lupus erythematosus patients following SARS-CoV-2 vaccination. Arthritis Rheumatol. 74, 284-294 (2022).

95. Braun-Moscovici, Y. et al. Disease activity and humoral response in patients with inflammatory rheumatic diseases after two doses of the Pfizer mRNA vaccine against SARS-CoV-2. Ann. Rheum. Dis. 80, 1317-1321 (2021)

96. Connolly, C. M. et al. Absence of humoral response after two-dose SARS-CoV-2 messenger RNA vaccination in patients with rheumatic and musculoskeletal diseases: a case series. Ann. Intern. Med. 174, 1332-1334 (2021).

97. Ruddy, J. A. et al. High antibody response to two-dose SARS-CoV-2 messenger RNA vaccination in patients with rheumatic and musculoskeletal diseases. Ann. Rheum. Dis. 80, 1351-1352 (2021).

98. Mahil, S. K. et al. The effect of methotrexate and targeted immunosuppression on humoral and cellular immune responses to the COVID-19 vaccine BNT162b2: a cohort study. Lancet Rheumatol. 3 , e627-e637 (2021).

99. Spiera, R., Jinich, S. \& Jannat-Khah, D. Rituximab, but not other antirheumatic therapies, is associated with impaired serological response to SARS-CoV-2 vaccination in patients with rheumatic diseases. Ann. Rheum. Dis. 80, 1357-1359 (2021).

100. Achiron, A. et al. Humoral immune response to COVID-19 mRNA vaccine in patients with multiple sclerosis treated with high-efficacy disease-modifying therapies. Ther. Adv. Neurol. Disord. 14 17562864211012835 (2021)

101. Moor, M. B. et al. Humoral and cellular responses to mRNA vaccines against SARS-CoV-2 in patients with a history of CD20 B-cell-depleting therapy (RituxiVac) an investigator-initiated, single-centre, open-label study. Lancet Rheumatol 3, e789-e797 (2021).

102. Mrak, D. et al. SARS-CoV-2 vaccination in rituximabtreated patients: B cells promote humoral immune responses in the presence of T-cell-mediated immunity. Ann. Rheum. Dis. 80, 1345-1350 (2021).

103. Rincon-Arevalo, H. et al. Impaired humoral immunity to SARS-CoV-2 BNT162b2 vaccine in kidney transplant recipients and dialysis patients. Sci. Immunol. 6 eabj1031 (2021)

104. Bingham, C. O. 3rd et al. Immunization responses in rheumatoid arthritis patients treated with rituximab: results from a controlled clinical trial. Arthritis Rheum. 62, 64-74 (2010).

105. van Assen, S. et al. Humoral responses after influenza vaccination are severely reduced in patients with rheumatoid arthritis treated with rituximab. Arthritis Rheum. 62, 75-81 (2010).

106. Vijenthira, A., Gong, I., Betschel, S. D., Cheung, M. $\&$ Hicks, L. K. Vaccine response following anti-CD20 therapy: a systematic review and meta-analysis of 905 patients. Blood Adv. 5, 2624-2643 (2021).

107. Stefanski, A. L. et al. B cell numbers predict humoral and cellular response upon SARS-CoV-2 vaccination among patients treated with rituximab. Arthritis Rheumatol. https://doi.org/10.1002/art.42060 (2021).

108. Bitoun, S. et al. Rituximab impairs B-cell response but not T-cell response to COVID-19 vaccine in auto-immune diseases. Arthritis Rheumatol. https://doi.org/10.1002/ art.42058 (2021).

109. Jinich, S., Schultz, K., Jannat-Khah, D. \& Spiera, R. $B$-cell reconstitution is strongly associated with COVID-19 vaccine responsiveness in rheumatic disease patients treated with rituximab. Arthritis Rheumatol. https://doi.org/10.1002/art.42034 (2021). 
110. Husain, S. A. et al. Postvaccine anti-SARS-CoV-2 spike protein antibody development in kidney transplant recipients. Kidney Int. Rep. 6, 1699-1700 (2021).

111. Hall, V. G. et al. Randomized trial of a third dose of mRNA-1 273 vaccine in transplant recipients. N. Engl. J. Med. 385, 1244-1246 (2021)

112. Connolly, C. M. et al. Temporary hold of mycophenolate augments humoral response to SARS-CoV-2 vaccination in patients with rheumatic and musculoskeletal diseases: a case series. Ann. Rheum. Dis. 81, 293-295 (2022).

113. Curtis, J. R. et al. American College of Rheumatology Guidance for COVID-19 vaccination in patients with rheumatic and musculoskeletal diseases: version 4. Arthritis Rheumatol. 73, e60-e75 (2021).

114. Chen, R. E. et al. Reduced antibody activity against SARS-CoV-2 B. 1.617.2 Delta virus in serum of mRNA-vaccinated patients receiving Tumor Necrosis Factor- $\alpha$ inhibitors. Med 2, 1327-1341 (2021)

115. Valor-Méndez, L. et al. Correspondence on "Immunogenicity and safety of anti-SARS-CoV-2 mRNA vaccines in patients with chronic inflammatory conditions and immunosuppressive therapy in a monocentric cohort". Ann. Rheum. Dis. 80, e161 (2021).

116. Boyarsky, B. J. et al. Antibody response to a single dose of SARS-CoV-2 mRNA vaccine in patients with rheumatic and musculoskeletal diseases. Ann. Rheum. Dis. https://doi.org/10.1136/annrheumdis-2021-220289 (2021).

117. Boyarsky, B. J. et al. Immunogenicity of a single dose of SARS-CoV-2 messenger RNA vaccine in solid organ transplant recipients. JAMA 325, 1784-1786 (2021).

118. Stefanski, A.-L. et al. B cell numbers predict humoral and cellular response upon SARS-CoV-2 vaccination among patients treated with rituximab. Arthritis Rheumatol. https://doi.org/10.1002/art.42060 (2021).

119. Chodick, G. et al. The effectiveness of the TWO-DOSE BNT162b2 vaccine: analysis of real-world data. Clin. Infect. Dis. https://doi.org/10.1093/cid/ciab438 (2021).

120. Tenforde, M. W. et al. Effectiveness of SARS-CoV-2 mRNA vaccines for preventing Covid-19 hospitalizations in the United States. Clin. Infect. Dis. https://doi.org/ 10.1093/cid/ciab687 (2021).

121. Brosh-Nissimov, T. et al. BNT162b2 vaccine breakthrough: clinical characteristics of 152 fully vaccinated hospitalized COVID-19 patients in Israel. Clin. Microbiol. Infect. 27, 1652-1657 (2021).

122. Juthani, P. V. et al. Hospitalisation among vaccine breakthrough COVID-19 infections. Lancet Infect. Dis. 21, 1485-1486 (2021)

123. Cook, C. et al. Clinical characteristics and outcomes of COVID-19 breakthrough infections among vaccinated patients with systemic autoimmune rheumatic diseases. Ann. Rheum. Dis. 81, 289-291 (2021).

124. Lawson-Tovey, S. et al. SARS-CoV-2 infection after vaccination in patients with inflammatory rheumatic and musculoskeletal diseases. Ann. Rheum. Dis. 81 145-150 (2021)

125. Mok, C. C. et al. Safety and immune response of live-attenuated herpes zoster vaccine in patients with systemic lupus erythematosus: a randomised placebocontrolled trial. Ann. Rheum. Dis. 78, 1663-1668 (2019).

126. Mok, C. C., Ho, L. Y., Fong, L. S. \& To, C. H Immunogenicity and safety of a quadrivalent human papillomavirus vaccine in patients with systemic lupus erythematosus: a case-control study. Ann. Rheum. Dis. 72, 659-664 (2013).

127. Stevens, E. et al. Safety of the zoster vaccine recombinant adjuvanted in rheumatoid arthritis and other systemic rheumatic disease patients: a single center's experience with 400 patients. ACR Open Rheumatol. 2, 357-361 (2020).

128. Lee, J. S. \& Shin, E.-C. The type I interferon response in COVID-19: implications for treatment. Nat. Rev. Immunol. 20, 585-586 (2020).

129. Sprent, J. \& King, C. COVID-19 vaccine side effects the positives about feeling bad. Sci. Immunol. 6, eabj9256 (2021)

130. Crow, M. K. Type I interferon in the pathogenesis of lupus. J. Immunol. 192, 5459-5468 (2014).

131. Furie, R. A. et al. Type I interferon inhibitor anifrolumab in active systemic lupus erythematosus (TULIP-1): a randomised, controlled, phase 3 trial. Lancet Rheumatol. 1, e208-e219 (2019).

132. Morand, E. F. et al. Trial of anifrolumab in active systemic lupus erythematosus. N. Engl. J. Med. 382, 211-221 (2020)

133. Pardi, N., Hogan, M. J., Porter, F. W. \& Weissman, D. mRNA vaccines - a new era in vaccinology. Nat. Rev. Drug Discov. 17, 261-279 (2018)

134. Barbhaiya, M., Levine, J. M., Bykerk, V. P., Jannat-Khah, D. \& Mandl, L. A. Systemic rheumatic disease flares after SARS-CoV-2 vaccination among rheumatology outpatients in New York City. Ann. Rheum. Dis. 80, 1352-1354 (2021)

135. Connolly, C. M. et al. Disease flare and reactogenicity in patients with rheumatic and musculoskeletal diseases following two-dose SARS-CoV-2 messenge RNA vaccination. Arthritis Rheumatol. 74, 28-32 (2021).

136. Bengtsson, A. A. \& Rönnblom, L. Role of interferons in SLE. Best. Pract. Res. Clin. Rheumatol. 31, 415-428 (2017).

137. Felten, R. et al. Tolerance of COVID-19 vaccination in patients with systemic lupus erythematosus: the international VACOLUP study. Lancet Rheumatol. 3 e613-e615 (2021)
138. Machado, P. M. et al Safety of vaccination against SARS-CoV-2 in people with rheumatic and musculoskeletal diseases: results from the EULAR Coronavirus Vaccine (COVAX) physician-reported registry. Ann. Rheum. Dis. https://doi.org/10.1136/ annrheumdis-2021-221490 (2021).

139. Curtis, J. R. et al. American College of Rheumatology Guidance for COVID-19 vaccination in patients with rheumatic and musculoskeletal diseases: version 3. Arthritis Rheumatol. 73, e60-e75 (2021).

140. Acevedo, M. L. et al. Infectivity and immune escape of the new SARS-CoV-2 variant of interest Lambda. Preprint at medRxiv https://doi.org/10.1101/ 2021.06.28.21259673 (2021).

141. Robinson, P. C., Yazdany, J. \& Machado, P. M. Clobal research collaboration in a pandemicchallenges and opportunities: the COVID-19 Global Rheumatology Alliance. Curr. Opin. Rheumatol. 33 $111-116$ (2021)

142. US National Institutes of Health. COVID-19 Treatment Guidelines. Clinical Spectrum of SARS-CoV-2 Infection onlinel, https://www. covid 19 treatmentguidelines.nih. gov/overview/clinical-spectrum/ (2021).

\section{Author contributions}

All authors contributed equally to all aspects of the article.

\section{Competing interests}

R.G. reports receiving speakers bureau honoraria from AbbVie Cornerstones and Janssen, consulting fees from AstraZeneca and Novartis, and non-financial support from Janssen and Pfizer. A.H.J.K. reports receiving research grant funding from GlaxoSmithKline, consulting fees from Alexion Pharmaceuticals, Aurinia Pharmaceuticals, Exagen Diagnostics and GlaxoSmithKline, and speakers bureau honoraria from Aurinia Pharmaceuticals, Exagen Diagnostics and GlaxoSmithKline. R.C. reports receiving speakers bureau honoraria from AbbVie, Janssen, Roche and Sanofi. J.Y. reports receiving research grant funding from AstraZeneca and Gilead and consulting fees from AstraZeneca, Aurinia, Eli Lilly and Pfizer. P.C.R. reports receiving personal fees from AbbVie, Atom Biosciences, Eli Lilly, Gilead, Janssen, Novartis, Pfizer, Roche and UCB, meeting-attendance support from Bristol Myers Squibb, Pfizer and UCB, and grant funding from Janssen, Novartis, Pfizer and UCB.

\section{Peer review information}

Nature Reviews Rheumatology thanks L. Calabrese and the other, anonymous, reviewer(s) for their contribution to the peer review of this work

\section{Publisher's note}

Springer Nature remains neutral with regard to jurisdictional claims in published maps and institutional affiliations.

(c) Crown 2022 